\title{
Biomimetic insulin-imprinted polymer nanoparticles as a potential oral drug delivery system*
}

PIJUSH KUMAR PAUL ${ }^{1}$

ALONGKOT TREETONG ${ }^{2}$

ROONGNAPA SUEDEE ${ }^{1, * *}$

${ }^{1}$ Molecular Recognition Materials Research Unit, Nanotec-PSU Center of Excellence on Drug Delivery System Department of Pharmaceutical Chemistry, Faculty of Pharmaceutical Sciences, Prince of Songkla University Hatyai, Songkhla 90112, Thailand

${ }^{2}$ National Nanotechnology Center (NANOTEC), National Science and Technology Development Agency (NSTDA), Thailand Science Park Phahonyothin Road

Pathum Thani 12120, Thailand

Accepted March 2, 2017

Published online April 6, 2017

\begin{abstract}
In this study, we investigate molecularly imprinted polymers (MIPs), which form a three-dimensional image of the region at and around the active binding sites of pharmaceutically active insulin or are analogous to $\beta$ cells bound to insulin. This approach was employed to create a welldefined structure within the nanospace cavities that make up functional monomers by cross-linking. The obtained MIPs exhibited a high adsorption capacity for the target insulin, which showed a significantly higher release of insulin in solution at $\mathrm{pH} 7.4$ than at $\mathrm{pH}$ 1.2. In vivo studies on diabetic Wistar rats showed that the fast onset within $2 \mathrm{~h}$ is similar to subcutaneous injection with a maximum at $4 \mathrm{~h}$, giving an engaged function responsible for the duration of glucose reduction for up to $24 \mathrm{~h}$. These MIPs, prepared as nanosized material, may open a new horizon for oral insulin delivery.
\end{abstract}

Keywords: molecularly imprinted polymers, insulin, nanoparticles, islet cells, oral drug delivery

Biomimetic materials are attractive agents that demonstrate the importance of inherent properties of efficiently delivering drugs to desired sites in the biological system (1). Recent evidence has shown that nanoparticles have a potential for delivering proteins, since they can offer protection from the digestive proteins in the gastrointestinal (GI) environment and provide biomacromolecule passage at the desired adsorption sites within the GI tract for systemic drug delivery (2). Molecularly imprinted polymers (MIPs) can serve as good drug delivery agents especially for peptides/proteins due to their high stability, drug loading capabilities and ease of preparation (3). Biomimetic systems using MIPs involve the nanoparticle-biomolecule association that can produce actual interactions between the initial templates and simulate biological recognition just as it does in replication (4). Furthermore, the use of nanoparticles in molecular imprinting on polymerization materials can be achieved with biomimetic carriers, including core-shell nanoparticles, microgels, cross-linked chains, chitosan, and quantum dots $(5,6)$. In mo-

\footnotetext{
* This work is dedicated to Professor Wolfgang Lindner on the occasion of his 75th birthday.

** Corresponding author; e-mail: roongnapa.s@psu.ac.th
} 
lecular imprinting, self-association of polymer nanoparticles with the template has produced multiple binding site points for the recognition of biologically important macromolecules within three dimensions of the polymer chains surrounding them (7). The MIPs designed with the coordinative effect of functional groups in the polymeric chain can bind a short peptide with high affinity (8). It has the preponderance of the uptake of protein structure on the lipid-protein bilayer, which is not only the binding affinity under the conditions but also the diversity of cell activities, reflecting the surface properties such as charge, chemical groups, and hydrophobic effect. A major advantage of molecular imprinting by precipitation polymerization is that it creates a selective nanoscale environment with increased affinity of specific functional groups at recognition sites that mimic the structure of the cell membrane surface layer. The possibility of differently targeted delivery by the imprinting approach, not just an alternative in enhancing selective drug delivery but the opportunity of being used as the key of biomolecule recognition, impacted the uptake of the drug or biomolecule into the cells (9). Nevertheless, good design of MIPs suitable for protein delivery still remains a challenge.

Insulin administered into the body can cause hypoglycemia or affect the elevated glucose level during transport via the route of administration into muscle cells and tissues. Insulin is typically administered through a subcutaneous route involving the risk of pain, infection, hyperinsulinemia, and deposition of fat around the injection site, which often leads to poor patient compliance (10). Therefore, oral delivery of insulin is of great interest owing to the benefit of an appropriate release rate of the payload in the GI tract over an extended period of time. In addition, insulin transport from the site of action needs to be investigated with the specific target of the lipid-protein or membrane assembly at the site. A previous report described the interaction of the exogenous insulin with the insulin receptor contained in rat pancreatic islets (11). In this work, we exploited molecular imprinting for generation of recognition sites of insulin binding to cell membranes of the islets. It is interesting to study the molecules and receptors present in the islets as imprinting templates for insulin binding. To our knowledge, no isolated/digested islets have been explored as an imprinting template in the literature. Exploiting the cross-linked $N, N$-methylene-bisacrylamide (MBAA) nanoparticles prepared from a single and mixed functional monomer of methacrylic acid (MAA) and $N$-hydroxyethyl acrylamide (HEAA) copolymer allows reversible complexation on MIP binding sites that emerged from the intrinsic property of a protein drug. Furthermore, the property of template imprinting on the polymer nanoparticle can affect the cellular uptake into blood circulation (12). The varying of ratios of the functional monomer and cross-linker can improve the selectivity and allow for specific adsorption of the insulin at the imprint site of the polymer. MIP nanoparticlebased carriers may enable the protection of the protein from degradation and its passage through the absorption barrier.

The goal of this work is to synthesize MBAA cross-linked nanoparticles consisting of different functional groups that will interact with the template. MAA exhibits mucoadhesive properties at higher concentrations (13) and the added HEAA functional monomer is a hydrophilic nonionic monomer with adhesive characteristics during the polymerization procedure (14) and thus can be anchored on the cross-linked chains of insulin-MIPs. Precipitation polymerization is a common technique for producing spherical particles with controlled size distribution (15). Pan et al. used precipitation polymerization for the preparation of protein-imprinted nanoparticles (16). The other advantages of this method are easy preparation, without addition of surfactants or stabilizers. This polymerization will 
form individual molecules via non-covalent interactions from a very specific functionality through the nanoparticle-protein association so that it can help improve the protein loading and delivery efficiency. The paper describes the preparation of a biomimetic insulin MIP-based nanocarrier for drug delivery.

\section{EXPERIMENTAL}

\section{Materials}

Methacrylic acid (MAA), N-hydroxyethyl acrylamide (HEAA), N,N-methylene-bisacrylamide (MBAA), polycaprolactone triol (PCL-T), collagenase, streptozotocin, and recombinant human insulin expressed in yeasts (proprietary host) were purchased from Sigma-Aldrich (USA). 2,2'-Azobis-(isobutyronitrile) (AIBN) was supplied by Wako Pure Chemical Industries Ltd. (Japan). MAA was distilled before use. Human insulin (recombinant DNA origin; $100 \mathrm{IU} / \mathrm{mL}$ ) was from Eli Lilly Asia, Inc., (Humulin ${ }^{\circledR} N$ ) and Novo Nordisk Pharma, Thailand (Insulatard ${ }^{\circledR} \mathrm{HM}$ ). All other reagents were of analytical grade and were used as received.

\section{Preparation of molecularly imprinted nanoparticles}

Insulin-imprinted nanoparticles were prepared by the precipitation polymerization method (17) using MBAA as a cross-linker in the presence of insulin or islet-bound insulin as the template in aqueous medium. The template and functional monomer mole ratio varied from 1:4 to 1:12 (Table I). Typically, MAA (1.6 mmol), HEAA (2.0 mmol), MBAA (8.5 $\mathrm{mmol})$, insulin $(35 \mathrm{mg})$, PCL-T $(0.05 \mathrm{mmol})$, and phosphate-buffered saline (PBS; $10 \mathrm{~mL})$ as a porogenic solvent were added into a $30 \mathrm{~mL}$ vial. After $30 \mathrm{~min}$ of stirring, a clear solution was obtained, to which AIBN $(0.04 \mathrm{mmol})$ was added. The vial was then purged with nitrogen and polymerized under a UV lamp at $254 \mathrm{~nm}$ wavelength for $12 \mathrm{~h}$ at room temperature $\left(25^{\circ} \mathrm{C}\right)$. At low temperature, the decomposition of AIBN was lower and produced low efficacy of free radicals, which affected the double-bond conversion of the formed product. Nonetheless, the appropriate duration of polymerization that provided the formed polymer product was determined by infrared (IR) spectroscopy. Monomers are water soluble; however, the solubility decreases due to the formation of oligomers during polymerization and the monomers are finally precipitated. The resultant insulin-imprinted polymers were collected by centrifugation at 10,000 rpm for $5 \mathrm{~min}$. After that, the adsorbed oligomers and unreacted monomers were removed from the MIP by washing with Milli-Q water. To remove the embedded insulin molecules from the polymer matrix, MIP nanoparticles were subsequently washed several times at room temperature with $0.5 \mathrm{~mol} \mathrm{~L}^{-1} \mathrm{NaCl}$ solution and Milli-Q water, and insulin removal from the prepared MIPs was tested using a UV-Vis spectrophotometer and analyzing the supernatant at the maximum wavelength $(272 \mathrm{~nm})$. Likewise, the non-imprinted polymer (NIP) nanoparticles were synthesized and washed, except for the omission of the template protein during the polymerization process.

\section{Isolation of rat pancreatic islets}

Wistar rats (200-250 g average body mass) were obtained from the Southern Laboratory Animal Facilities of the Prince of Songkla University. Experimental animals were maintained 
on a dry pellet diet and water ad libitum. Rats were fed in standard propylene cages and acclimatized for 7 days to animal house conditions in an air-conditioned room, (temperature 22 $\pm 3{ }^{\circ} \mathrm{C}$ ), relative humidity $46-70 \%, 12: 12 \mathrm{~h}$ light/dark cycle, adequate cross-ventilation), in accordance with the Ethical Committee (Ref. 36/2014). Fasting animals were deprived of food for at least $16 \mathrm{~h}$ but had free access to drinking water. Rats were sacrificed by cervical dislocation to obtain the pancreatic islets. Collagenase $\left(0.8 \mathrm{mg} \mathrm{mL}^{-1}\right)$ dissolved in Hank's buffered salt solution (HBSS) was injected into numerous lobes of the pancreas; the pancreas was then removed and digested for 15 to $20 \mathrm{~min}$ at $37^{\circ} \mathrm{C}$. Islets of Langerhans within the pancreas were collected by centrifugation three times with cooled HBSS at $5^{\circ} \mathrm{C}$, at $1000 \mathrm{rpm}$ for $1 \mathrm{~min}(18)$. A previous study has reported that insulin receptors on rat pancreatic islets bind to human insulin in a similar fashion as pork insulin (11). Immediately after the collection of islets, another batch of MIPs was prepared. The freshly isolated islets (about 100 islets) were incubated in $10 \mathrm{~mL}$ of PBS (pH 7.4) containing insulin (35 mg) at room temperature for $20 \mathrm{~min}$, followed by the addition of MAA, HEAA, MBAA, and PCL-T under continuous stirring. Upon addition of AIBN, polymerization occurred and the islet-bound insulin-imprinted polymers (MIPs) were collected in a similar way to that described previously.

\section{Particle size and $z$ potentials}

Average particle sizes and the z potential of MIP/NIP nanoparticles were determined using a Nanoparticle Analyzer (Zetasizer Nano ZS; Malvern Instruments Ltd., UK). Particle size was measured using the dynamic light scattering (DLS) technique. The samples were dispersed in PBS ( $\mathrm{pH} 7.4 ; 0.2 \mathrm{mg} \mathrm{mL}^{-1}$ ), followed by filtration through a $0.45 \mu \mathrm{m}$ filter and were then ultrasonicated for $10 \mathrm{~min}$ at room temperature. Measurements were carried out at an angle of $90^{\circ}$ at $25^{\circ} \mathrm{C}$. For z potential measurements, the samples were diluted in Milli-Q water. Each sample was analyzed in triplicate.

\section{Morphological observations}

Surface morphology of MIP nanoparticles was examined by scanning electron microscopy (SEM Quanta 400; FEI, Brno, Czech Republic). The sample was placed on an aluminum stub and coated with gold using a sputter coater in an argon atmosphere for $120 \mathrm{~s}$. TEM was used to observe MIPs after removal of the template applying an established washing protocol in the preparation process. For TEM measurements, the particles in PBS were dropped onto a carbon-coated copper grid and then observed with a JEM 2100F (Japan).

\section{Pore size distribution and surface area analysis}

Pore size distribution and surface areas of washed polymers were determined using the Brunauer-Emmett-Teller (BET) analysis with an automated gas sorption system (Quantachrome Autosorb-1, USA). Relevant information was obtained as follows: the pore size and porosity data were obtained from a plot of pore size versus incremental pore volume to give the pore size distribution using the Barrett-Joyner-Halenda (BJH) method. A plot of pore size versus pore volume gave the total pore volume with an indication of the surface areas and total pore volumes of the polymers. In addition, the incremental volume that was depleted with changes of each pressure was determined by the change in capacitance of the stem. The intrusion volume was recorded for the respective pressure or pore size. 


\section{AFM and AFM-confocal Raman spectroscopy}

In this study, the topography and surface geometry of the particles were examined by the combined method of AFM and Raman spectroscopy, because the environmental conditions can affect the interaction of particles and biological entities in different ways of drug release. Non-contact mode AFM (SPA-400-SPI4000; Seiko Instrument, Inc., Japan) was used to test the assembly and morphology of the nanostructure. A silicone cantilever with a spring constant of $12 \mathrm{~N} \mathrm{~m}^{-1}$ was employed. Topographic and phase images were collected at a scan rate of $1 \mathrm{~Hz}$ under ambient laboratory conditions. The images were further analyzed by the Nano Navi SPA400 (DFM) software. Raman spectra were collected with an AFM-confocal Raman spectrometer (NT-MDT model, Moscow, Russia) and NTEGRA Spectra equipped with hybrid mode (HD-AFM). The $632.8 \mathrm{~nm}$ excitation wavelength of a diode laser was focused onto the sample with a dry objective lens of $100 \times$ of 0.95 numerical aperture number (NA). The Stokes-shifted Raman scattering was recorded with 1200 grove $\mathrm{min}^{-1}$ grating using a Peltier-cooled charged-coupled device (CCD; Andor Technology PLC, CA, USA).

\section{Protein adsorption experiments}

Protein adsorption experiments on MIPs and NIPs were performed in PBS (pH 7.4). The respective polymers $(5 \mathrm{mg}$ ) were suspended in $5 \mathrm{~mL}$ of different insulin solutions in concentrations that ranged from 5 to $30 \mathrm{\mu g} \mathrm{mL}^{-1}$ at room temperature. After filtration with cellulose acetate (CA) membrane filters $(25 \mathrm{~mm}, 0.45 \mu \mathrm{m}$; Vertical Chromatography Co., Ltd., Bangkok, Thailand), the supernatant was analyzed using a Carry 60 UV-Vis spectrophotometer (Agilent Technologies) at a wavelength of $272 \mathrm{~nm}$, since this would not interfere with the solvent and the excess of the matrix upon incubation with the polymer. The amount of the specifically and/or non-specifically adsorbed insulin in the polymers and the polymer matrix was calculated using the formula:

$$
Q=\left(C_{0}-C\right) \times V / 1000 \times W
$$

where $Q$ is the amount of adsorbed insulin $\left(\mathrm{mg} \mathrm{g}^{-1}\right) ; C_{\mathrm{o}}$ and $C$ are the initial and final concentrations of insulin $\left(\mu \mathrm{g} \mathrm{mL} \mathrm{L}^{-1}\right)$, respectively; $V$ is the volume of the solution $(\mathrm{mL})$; and $W$ is the polymer mass (g) (19). Each experiment was repeated three times. The binding parameters were determined from the Scatchard equation:

$$
B / F=\left(B_{\max }-B\right) / K_{\mathrm{d}}
$$

where $K_{\mathrm{d}}$ and $B_{\max }$ are the equilibrium dissociation constant and the apparent maximum number of the binding sites, respectively. The amounts of insulin adsorbed $(B)$ were obtained from absorbance determination. $F$ represents the amount of insulin remaining in the supernatants. Adsorption kinetic experiments were carried out by adding $10 \mathrm{mg}$ polymer to $50 \mathrm{~mL}$ of a $10 \mu \mathrm{g} \mathrm{mL} \mathrm{m}^{-1}$ insulin solution in PBS solution at room temperature. The amounts of adsorbed protein on MIP/NIP nanoparticles were then evaluated with a UVVis spectrophotometer, as mentioned earlier. Bomb calorimetry using Isoperibol bomb calorimetry (IKA ${ }^{\circledR}$ Calorimeter System C5000 Control, Germany) was used to determine the gross heating value of the polymer incubated with insulin. 


\section{Protein release studies}

The in vitro release of the protein was studied by carrying out the adsorption of insulin onto the MIP and NIP nanoparticles with an initial insulin concentration of $100 \mu \mathrm{gL}^{-1}$ at $37^{\circ} \mathrm{C}$ in PBS (pH 7.4). After incubation, the nanoparticles were collected by centrifugation at 10,000 rpm for $20 \mathrm{~min}$. The samples (centrifuged) were then dispersed in buffer solutions of $\mathrm{pH} 1.2$ and $\mathrm{pH} 7.4$ at $37^{\circ} \mathrm{C}$. At specific time intervals, the amounts of insulin released in the supernatant were assayed by UV-Vis analysis following centrifugation (16). Experiments were performed in triplicate.

\section{In vivo evaluation}

Male Wistar rats (200-250 g) were obtained from the Southern Laboratory Animal facilities of the Prince of Songkla University, Thailand (Ethical No. 36/2014). Diabetes was induced in rats by an intraperitoneal injection of streptozotocin $\left(35 \mathrm{mg} \mathrm{kg}^{-1}\right)$ dissolved in citrate buffer ( $\mathrm{pH}$ 4.5) (20). After 3 days of injection, rats were considered to be diabetic when the glycaemia was above $250 \mathrm{mg} \mathrm{dL}^{-1}$. The animals were fasted overnight (water ad libitum) and remained fasted during the whole experiment. There were seven groups of animals, each group containing five diabetic rats. The first two groups of rats were given orally MIP1 (170 mg kg-1, single monomer MAA) and MIP2 (150 $\mathrm{mg} \mathrm{kg}^{-1}$, mixed functional monomer MAA and HEAA) loaded with insulin (50 IU kg-1). The rats of the next two groups were administered orally the respective NIP nanoparticles loaded with insulin (50 $\mathrm{IU} \mathrm{kg}{ }^{-1}$ ). The fifth group received an insulin solution orally $\left(50 \mathrm{IU} \mathrm{kg}^{-1}\right)$. The rats of the placebo control group were orally administered MIP nanoparticles (without insulin). Insulin formulation alone was given subcutaneously $\left(1 \mathrm{IU} \mathrm{kg}^{-1}\right)$ to the last group of rats. Blood samples were collected from the tail vein and the blood glucose level was measured using a glucose meter (Accu-Chek ${ }^{\circledR}$ Performa; Roche Diagnostics $\mathrm{GmbH}$, Germany) at predetermined time points. Pharmacological bioavailability (PA \%) of insulin-loaded nanoparticles after oral administration was calculated according to the following formula (21):

$$
\mathrm{PA}(\%)=\left([\mathrm{AAC}]_{\text {p.o. }} /[\mathrm{AAC}]_{\text {s.c. }}\right) \times\left(\text { Dose }_{\text {s.c. }} / \text { Dose }_{\text {p.o. }}\right) \times 100
$$

where $[\mathrm{AAC}]_{\text {p.o. }}$ and $[\mathrm{AAC}]_{\text {s.c. }}$ represent the area above the blood glucose level-time curve of oral and subcutaneous insulin formulation, respectively, and Dose $\mathrm{p}_{\text {p.o. }}$ and Dose $\mathrm{Dsc.}_{\text {.. }}$ are the oral and subcutaneous doses given. AAC were calculated by applying the trapezoidal rule (22). One-way analysis of variance (ANOVA), followed by Tukey's test, was used for statistical analysis; $p<0.05$ was considered to be statistically significant.

\section{RESULTS AND DISCUSSION}

\section{Synthesis and characterization of MIPs}

In this report, we chose molecular imprinting to investigate the recognition of pharmaceutically active insulin (F1) and rat islet-bound insulin (F2) as templates. Scheme 1 gives a schematic representation of the recognition of the insulin molecule at a binding pocket site prepared by aqueous precipitation polymerization. Varying the amount of 


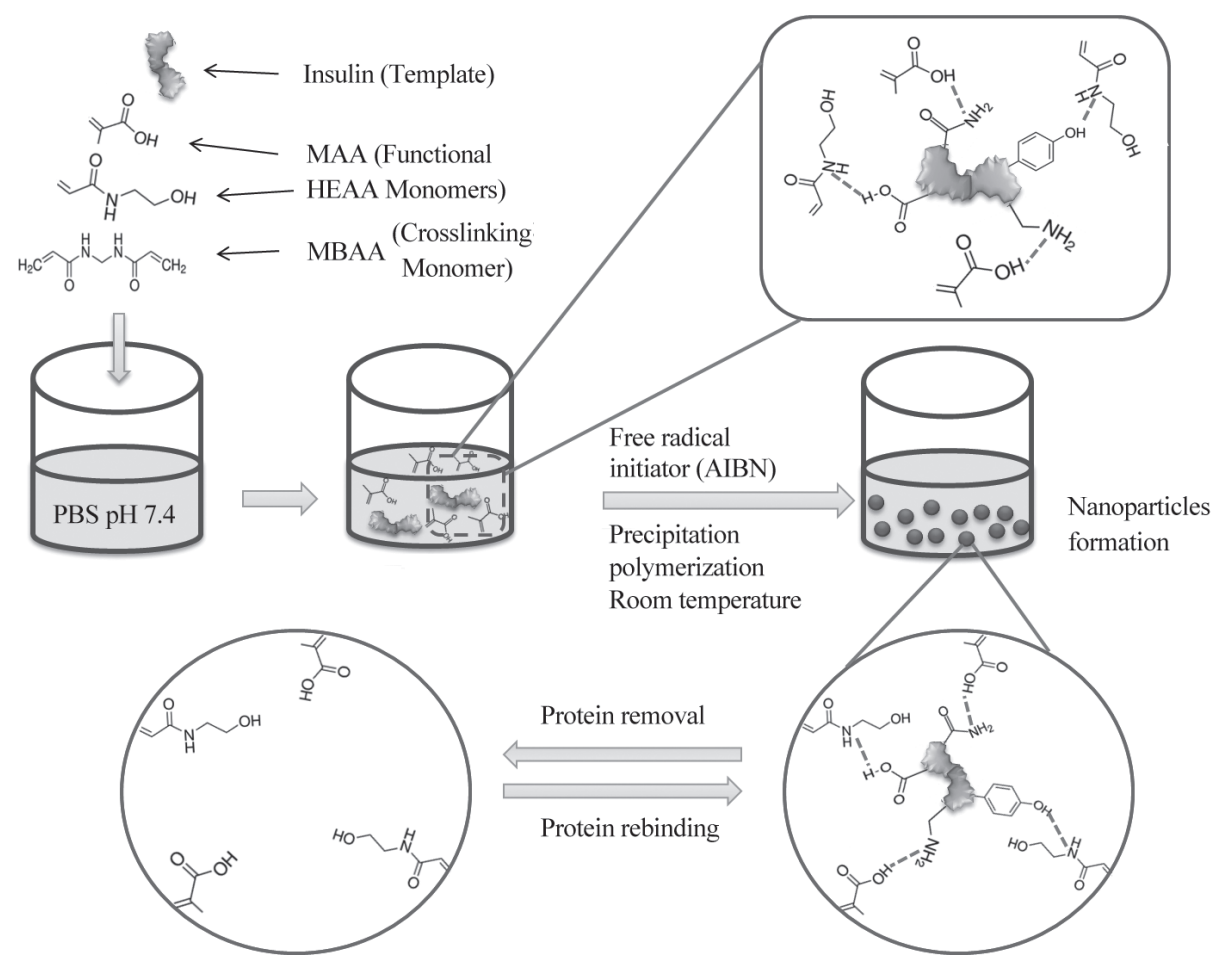

Scheme 1.

Table I. Polymeric composition of MIPs and NIPs nanoparticles

\begin{tabular}{|c|c|c|c|c|c|c|}
\hline $\begin{array}{l}\text { Compd. } \\
\text { (mmol) }\end{array}$ & MIP1 & MIP2 & MIP3 & MIP4 & NIP1 & NIP2 \\
\hline Template & $\begin{array}{c}\text { Humulin }{ }^{\circledR} N \\
0.6\end{array}$ & $\begin{array}{c}\text { Humulin }{ }^{\circledR} N \\
0.6\end{array}$ & $\begin{array}{c}\text { Insulatard }^{\circledR} \mathrm{HM} \\
0.6\end{array}$ & $\begin{array}{c}\text { Insulatard }^{\circledR} \mathrm{HM} \\
0.6\end{array}$ & - & - \\
\hline MAA & 1.6 & 5.0 & 1.6 & 5.0 & 1.6 & 5.0 \\
\hline HEAA & - & 2.0 & - & 2.0 & - & 2.0 \\
\hline MBAA & 8.5 & 3.2 & 8.5 & 3.2 & 8.5 & 3.2 \\
\hline PCL-T & 0.05 & 0.05 & 0.05 & 0.05 & 0.05 & 0.05 \\
\hline AIBN & 0.04 & 0.04 & 0.04 & 0.04 & 0.04 & 0.04 \\
\hline
\end{tabular}

MBAA as well as the concentrations of MAA and HEAA (Table I) led to the formation of MIPs, resulting in insulin affinity to the binding sites within the polymer matrix. MIP1 contains a single functional monomer (MAA) with high cross-linking whereas MIP2 com- 

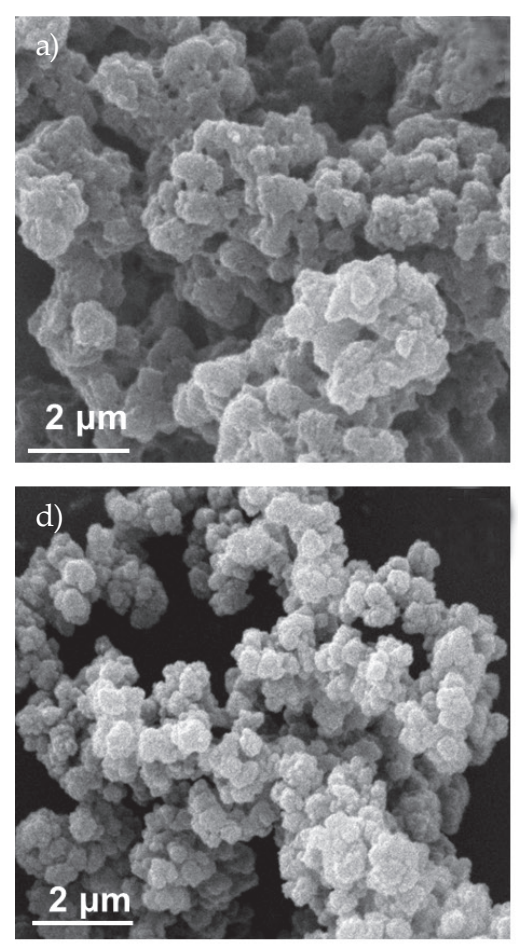

b)

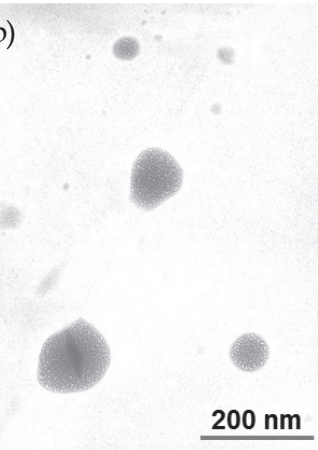

e)

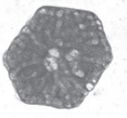

c)

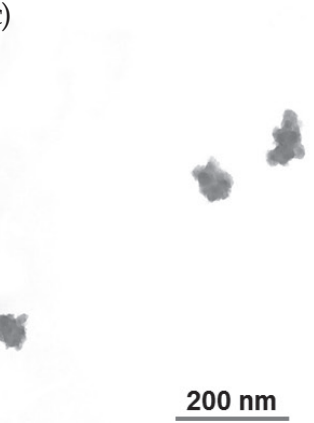

f)

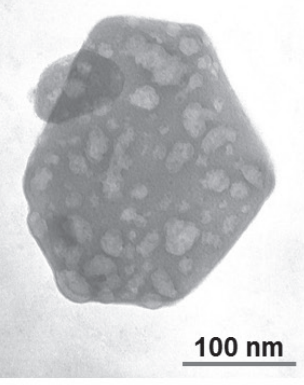

g)

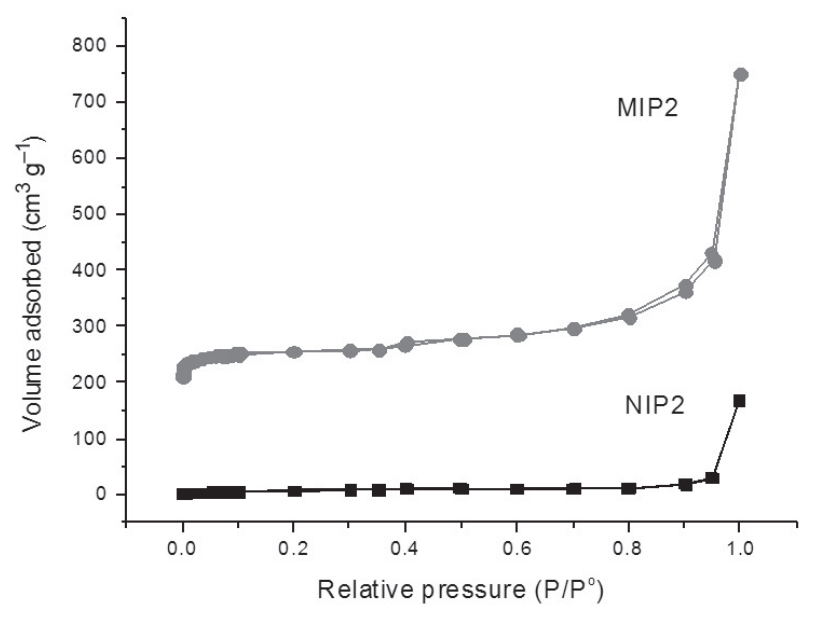

Fig. 1. a) and d) SEM, b), c), e) and f) TEM images of insulin and insulin imprinted polymers. e) the surface morphology of insulin. b) and f) TEM images showing the more porous structure of MIP than that of NIP (c). Micrograph A represents the rough surface of MIP compared to NIP (d). g) Nitrogen adsorption/desorption isotherms of MIPs compared to NIPs. 
P. Kumar Paul et al.: Biomimetic insulin-imprinted polymer nanoparticles as a potential oral drug delivery system, Acta Pharm. 67 (2017) 149-168.

Table II. Characteristics of the insulin imprinted nanoparticles

\begin{tabular}{lcccccc}
\hline & \multicolumn{3}{c}{ Without islets (F1) } & \multicolumn{3}{c}{ With islets (F2) } \\
\cline { 2 - 7 } Polymer & $\begin{array}{c}\text { Mean } \\
\text { diameter } \\
(\mathrm{nm})\end{array}$ & \multicolumn{1}{c}{ PDI $^{\mathrm{a}}$} & $\begin{array}{c}\text { Zeta } \\
\text { potential } \\
(\mathrm{mV})\end{array}$ & $\begin{array}{c}\text { Mean } \\
\text { diameter } \\
(\mathrm{nm})\end{array}$ & PDI & $\begin{array}{c}\text { Zeta } \\
\text { potential } \\
(\mathrm{mV})\end{array}$ \\
\hline MIP1 & $221.86 \pm 23.55$ & $0.39 \pm 0.03$ & $-32.2 \pm 5.1$ & $200.46 \pm 7.8$ & $0.37 \pm 0.01$ & $-28.1 \pm 3$ \\
MIP2 & $198.73 \pm 3.05$ & $0.33 \pm 0.02$ & $-32.3 \pm 4.23$ & $195.03 \pm 3.11$ & $0.34 \pm 0.05$ & $-24.8 \pm 2.48$ \\
MIP3 & $214.56 \pm 24.54$ & $0.38 \pm 0.05$ & $-19.7 \pm 3.21$ & $199.13 \pm 9.36$ & $0.33 \pm 0.02$ & $-29 \pm 3.26$ \\
MIP4 & $199.73 \pm 5.9$ & $0.34 \pm 0.01$ & $-30.4 \pm 4.1$ & $194.6 \pm 8.17$ & $0.35 \pm 0.01$ & $-31 \pm 4.1$ \\
NIP1 & $302.46 \pm 10.5$ & $0.46 \pm 0.08$ & $-28.9 \pm 3.7$ & $204.13 \pm 5.09$ & $0.37 \pm 0.02$ & $-29.1 \pm 3.4$ \\
NIP2 & $236.56 \pm 31.33$ & $0.43 \pm 0.05$ & $-33.6 \pm 2.3$ & $201.1 \pm 16.21$ & $0.35 \pm 0.02$ & $-29.8 \pm 2.77$ \\
\hline
\end{tabular}

a PDI - polydispersity index; mean $\pm \mathrm{SD}(n=3)$.

prises two functional monomers (MAA and HEAA) with lower cross-linking. MIP3 and MIP4 are similar to MIP1 and MIP2, except for the different insulin source (pharmaceutical company). Sizes obtained from the light scattering measurements are shown in Table II. Clearly, a slight decrease in particle size was observed, which was associated with an increase in the functional monomer concentration and the addition of a second monomer (HEAA) resulting from the interaction between the protein template and the surrounding monomers during polymerization.

SEM and TEM were used to examine the surface morphology and nanoparticle size of the formed MIP nanoparticles (Fig. 1a-e). In both SEM (Fig. 1a) and TEM (Fig. 1b), MIPs exhibited greater roughness and porous morphology than NIPs (Fig. 1d and c) due to the interaction of insulin with the functional monomer, which was finally washed out after polymerization. Further, the light scattering data of MIP nanoparticles revealed particle size ranges from 200 to $220 \mathrm{~nm}$. This was confirmed by TEM observations, as shown in Fig. $1 \mathrm{~b}$-f. The optimum size ranged from 50 to $500 \mathrm{~nm}$ for the interaction between nanoparticles and epithelial cells (23). Therefore, MIPs could be suitable candidates for the transport of insulin across the cell membrane.

It is noteworthy that the PDI values of approximately 0.3 were found in all cases of MIPs. In contrast, NIP nanoparticles showed a higher PDI value of about 0.4 with higher particle size ranges from 230 to $300 \mathrm{~nm}$. The results indicated the effect of template protein on the formation of MIP nanoparticles with homogeneous dispersion during the polymerization process. Although no template was added for NIP during polymerization, this resulted in a slightly broader size distribution compared to MIP. The z potentials of all imprinted nanoparticles were negative, as shown in Table II. As can be seen, MIPs produced with a mixed functional monomer had a lower surface charge than their corresponding NIPs, whereas the single functional monomer in F1 and the control polymer showed no differences in particle surface charges. The z potential of F1 was found slightly increased, whilst there was a relatively higher z potential value of MIP3 of F2 than of F1. This led to an increase in accessibility of the biotherapeutic molecule to the binding site 
within the MIP; hence higher adsorption for MIP3 $\left(2.69 \mathrm{mg} \mathrm{g}^{-1}\right)$. This result could be explained by the presence of zwitterionic molecules on the nanoparticles, caused by the bound insulin and $N$-linked glycoproteins on the rat $\mathrm{b}$ cells that self-assembled some structural motifs into polymer F2 $(24,25)$. The negative surface charge of MIPs varied between -20 and $-33 \mathrm{mV}$ and contained the hydrophilic functionalities on the MIP binding sites and the negatively charged side chains. The generation of insulin MIP nanoparticles in this study involved two point interactions of the insulin with the MAA and HEAA as a mixed functional monomer, forming an interaction with each of the amine and carbonyl moieties of the islets that would cause a strong interaction with the complementary template, hence expected the MIP show the intrinsic $\beta$ cells-bound insulin template. Furthermore, this negative surface charge could allow them to diffuse into the mucus as a result of less interaction with the mucin $(26,27)$.

\section{Surface area and pore size distribution of insulin MIPs}

Macroscopic characteristics of MIPs and NIPs were examined by pore analysis such as the surface area, pore volume, and pore diameter of all of the synthesized materials. In supplemental data (Table S1), the mixture of a larger amount of the two monomers in MIP2 (MAA and HEAA) showed a larger surface area $\left(149.1 \mathrm{~m}^{2} \mathrm{~g}^{-1}\right)$, whereas a bigger quantity of the cross-linker (MBAA) generated a smaller surface area $\left(21.83 \mathrm{~m}^{2} \mathrm{~g}^{-1}\right)$ for MIP1. A similar trend was observed for MIP3 and MIP4. A large surface area of particles would lead to smaller particle sizes. BET analysis also demonstrated the presence of mesopores of about $20 \mathrm{~nm}$ for the polymer, leading to similar characteristics to those of a type IV isotherm, so their nanospace pores can be distinguished from NIPs. In the case of NIPs, the pore diameter was larger and the isotherm exhibited a type III curve characteristic due to the nonporous structure with low interaction (28). That insulin recognition sites formed within the nanospace pores was further corroborated by a bomb calorimeter. After incubation with insulin (suspension formulation, Novo Nordisk Pharma, Thailand), the gross heating value was almost similar for both MIP and NIP (see Table S2). Evidently, with insulin (crystalline powder form, Sigma-Aldrich, USA), the gross heating value was $16,844 \mathrm{~J} \mathrm{~g}^{-1}$ for MIP2 and 13,518 $\mathrm{J} \mathrm{g}^{-1}$ for NIP2. This differential energy proved self-organization of the polymer in the medium that formed the biomimetic system. This result indicates the absence of surface adaptations of peptides after the template removal.

\section{AFM studies}

Fig. 2 shows the AFM image of the fine structure of insulin over the surface near the closely packed barrier of the nanoparticles for MIP1. It can be seen that there was a cloud-like blanket for MIP1, F1 (see Fig. 2f), and the distance between the interval of the neighboring nanoparticles and the individual pores was much smaller compared to that of the NIP1. The AFM image of the imprint with islets (MIP2) showed particle floccules, a worm-like cavity due to elastic interaction, and a larger overlap of surface coverage that resulted from adhesion of the induced association of the protein on the polymer to extend more, so that it was difficult to distinguish in the AFM image, as shown in Fig. 2f. The nanoscale contact geometry of the cavities was measured and found to be $2 \times 25 \times 25 \mathrm{~nm}$ (height $\times$ length $\times$ width) for MIPs, as shown in Fig. 3a-e. According to the protein database, the size of the insulin hexamer is $3.5 \times 5 \mathrm{~nm}$ and contains $\mathrm{Zn}$ as a coordinating atom (29). The three-dimensional 
a)
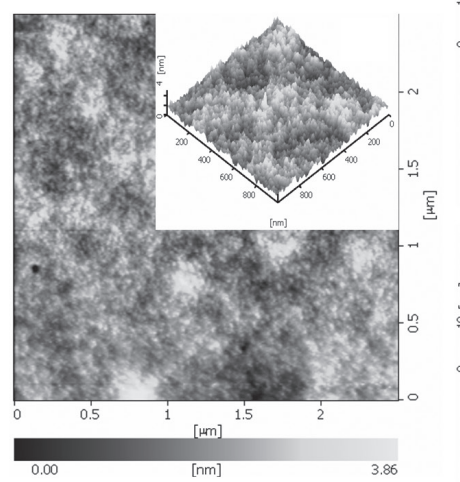

b)

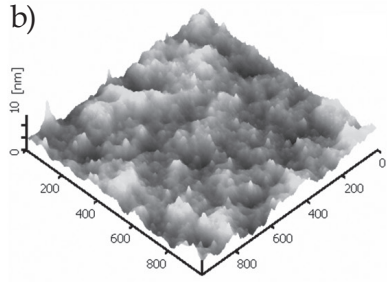

$[\mathrm{nm}]$

d)

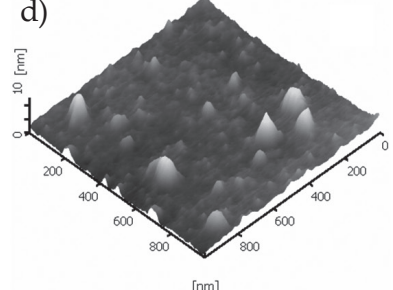

$[\mathrm{nm}]$

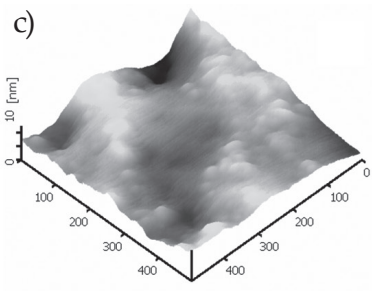

[nm]

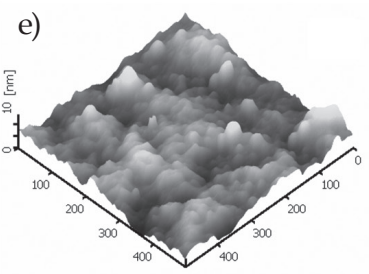

f)
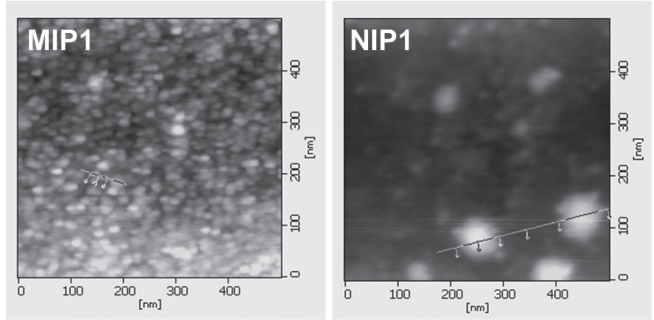

$[\mathrm{nm}]$
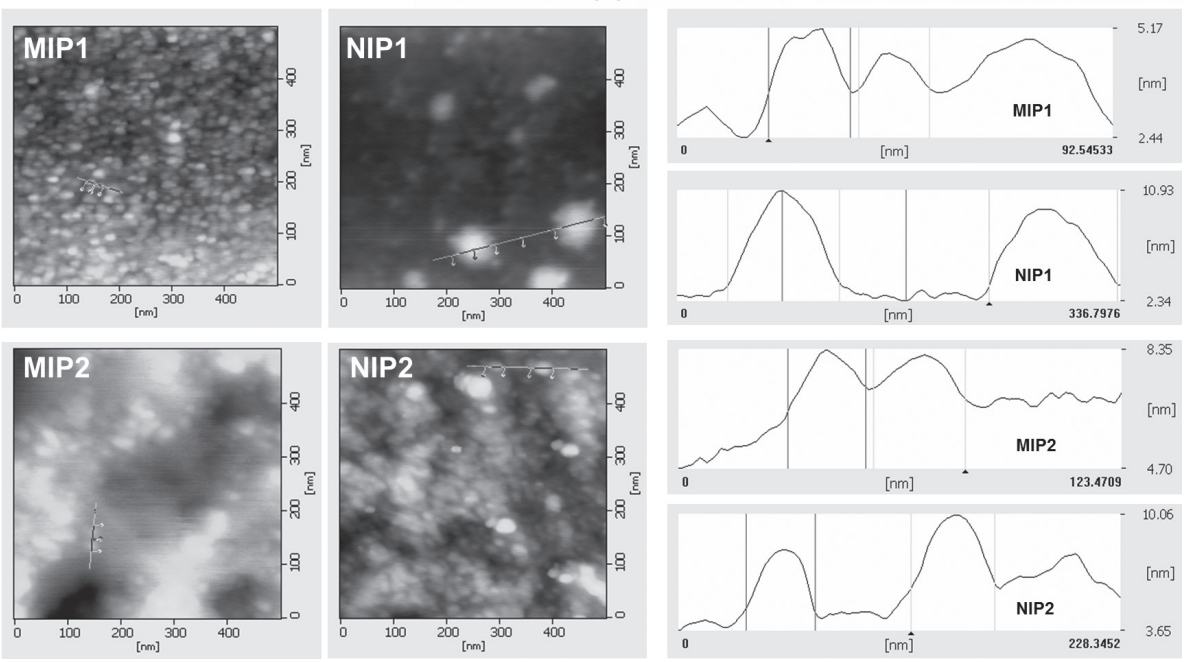

Fig. 2. a) Non-contact mode AFM of insulin, b) and c) surface topography of MIPs, d) and e) NIPs. This indicates the functionality of protein imprint after removal of the template. b) and d) represent $\mathrm{F} 1$ and c) and e) F2. f) AFM images of the colloidal patterns and 2D topography of the polymer surface with individual internal structures.

structure of both MIP1 (Fig. 3b) and MIP2 (Fig. 3c) indicates that they can accommodate the template protein with a size of the remaining cavity similar to the surface and possibly the geometrical change of the imprinted materials. Larger size of the cavity was observed for either the NIP1 (Fig. 3d) or NIP2 (Fig. 3e), each showing a shallow pore on the surface. Evidently, the AFM images confirmed successful generation of synthesized MIP nanoparticles after removal of the protein that formed the accommodated bionanomaterial inside the nanopore on the resultant synthetic materials. This was also related to insulin geometry. 


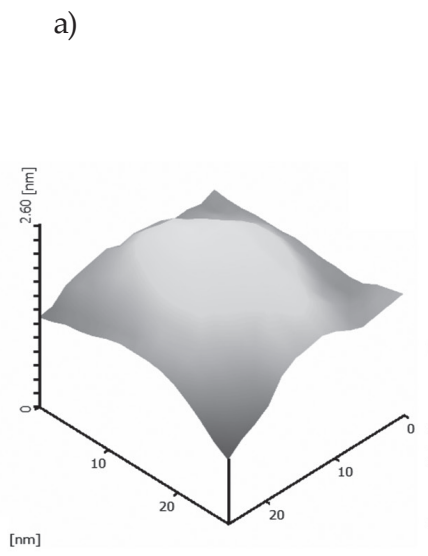

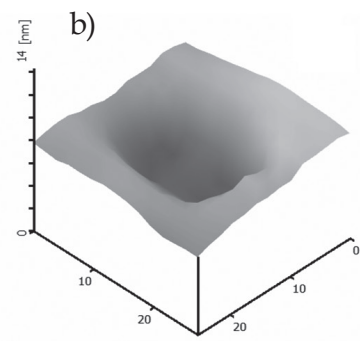

d)

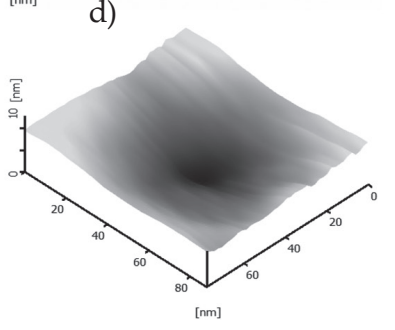

f)

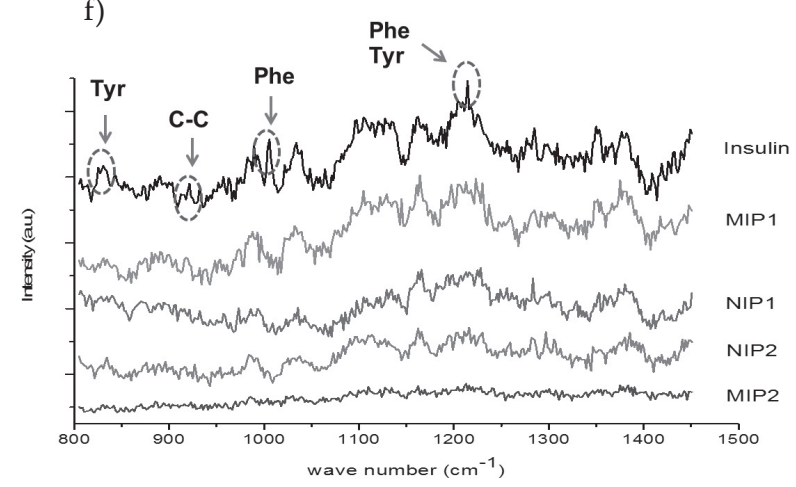

Fig. 3. AFM images of the imprinted cavity remaining after template removal. a) the nanoscale contact geometry of insulin molecule, b) and c) the imprinted cavities for MIP1 and MIP2, d) and e) the imprinted cavities for NIP1 and NIP2. b) and d) F1, c) and e) F2. Below: The difference between the imprint pattern and internal structure of insulin on the surface of nanoparticles. f) Raman spectra of insulin and MIPs with their corresponding NIP.

\section{Raman-AFM study}

We used confocal Raman spectroscopy to evaluate the structural information of biological entities in the protein template that remained in the synthesized nanoparticles. Fig. $3 \mathrm{f}$ illustrates the surface-enhanced Raman-AFM of the insulin and MIPs, showing different functional groups of interaction with the template that had an insulin imprint. The MIPs show the cluster of ridges and the grooves in the AFM image, which isolated a diameter of $\sim 5 \mathrm{~nm}$ of an active trench attached to the structure of the nanoparticle surface. Table III shows Raman data obtained from the AFM-Raman studies for insulin and polymers. 
P. Kumar Paul et al.: Biomimetic insulin-imprinted polymer nanoparticles as a potential oral drug delivery system, Acta Pharm. 67 (2017) 149-168.

Table III. Raman data of the insulin and polymers

\begin{tabular}{lcccccc}
\hline \multirow{2}{*}{ Raman peak } & \multirow{2}{*}{$\begin{array}{c}\text { Raman } \\
\text { shift }\left(\mathrm{cm}^{-1}\right)\end{array}$} & Insulin & MIP1 & MIP2 & NIP1 & NIP2 \\
\cline { 3 - 7 } & 832.53 & 464.38 & 330.25 & 45.56 & 306.33 & 250.92 \\
\hline Tyrosine (Tyr) & 940.24 & 307.84 & 279.05 & 66.66 & 175.59 & 162.64 \\
C-C & 1010.98 & 369.50 & 332.96 & 85.14 & 133.21 & 164.16 \\
Phenylalanine (Phe) & 1215.25 & 1005.62 & 743.97 & 154.27 & 470.31 & 421.45 \\
Tyr and Phe & & & & & & \\
\hline
\end{tabular}

The selected insulin in the Raman spectra was found at a different wave number, for example, tyrosine (Tyr) at $832 \mathrm{~cm}^{-1}$, phenylalanine (Phe) at $1010 \mathrm{~cm}^{-1}$, and the $1215 \mathrm{~cm}^{-1}$ band for Tyr and Phe residues outside the polymer cross-linked chains, which is well known to be characteristic for $R_{6}$ conformation of hexameric human insulin (29). The Raman shift at $1010 \mathrm{~cm}^{-1}$ can be used to confirm the intrinsic property of insulin formulation in the nanoscale environment of MIP1 (Fig. 3f). In contrast, the present method of generating the nanotopography for MIP2 was made to inhibit the Tyr and Phe residues in Raman spectra, allowing for the gap size of the captured surface to be probed. However, the oriented insulin indicated the structure and direction of peptide changes upon the template binding for MIPs. Dynamically, there was a far better interaction of the bulk layer of insulin than that of insulin in the pancreas islets with the MIP layer, which clearly showed the absence of a Raman peak shift for the islet imprint. For both NIPs, the spatial motifs of the insulin template were not fully distinguishable from the Raman shift.

\section{Recognition ability of insulin MIPs}

The recognition ability of the template for both the insulin-imprinted polymers and the corresponding NIPs was examined by batch binding experiments. Figs. $4 \mathrm{a}$ and $\mathrm{b}$ show the adsorption kinetic process of the protein to MIP and NIP nanoparticles. It can be seen that the MIPs of all formulations exhibited much higher adsorption capacities. Almost $80 \%$ of equilibrium adsorption was achieved within $30 \mathrm{~min}$ and reached a steady-state for adsorption at around $2 \mathrm{~h}$ for both the F1 and F2 formulations. This was attributed to the high recognition efficiency of the template protein for the imprinting sites because of the nanoscale sizes of the imprinted cavity fitting to template structure through better diffusion properties (17). In contrast to NIPs, the adsorption of insulin was lower than that for MIPs due to the imprinting process. In addition, MIP2 showed a comparatively higher adsorption capacity than MIP1 for insulin, which was apparently different from that of MIP2, so a smaller amount of cross-linker contributed more than in the single monomer, as reported by previous studies (30). From the protein adsorption data, it is clear that MIPs adsorbed insulin more efficiently than NIPs. Between the two different mole ratios - a low mole ratio of MBAA containing the HEAA copolymer produced a relatively high density of binding sites, whereas a high mole ratio of cross-linkers and MAA lowered the imprinting efficiency of MIPs (31). This can be attributed to the different ratio of the amino acidsurface insulin on the imprinted cavities allowed for recognition sites, emphasizing the importance of the initial flexible conformation of protein (32). 


\section{Binding isotherms}

The recognition behavior, which was dependent on the concentration of insulin in solution, was investigated to obtain the binding isotherm using insulin in a $\mathrm{pH} 7.4$ buffer solution. The binding isotherm curves (Fig. $4 \mathrm{c}$ and d) show that the adsorption capacity of MIP nanoparticles was increased with an increase in the initial concentration of insulin in comparison with NIPs. Maximum adsorption capacity was obtained by MIP2 for both F1 and F2 formulations (3.26 and $3.34 \mathrm{mg} \mathrm{g}^{-1}$, respectively). The Scatchard plots of insulin binding to MIP1 and MIP2 nanoparticles are shown in the insets (Fig. 4c and d) and the binding parameters are given in Table S3. This revealed a single straight line and implied the presence of homogeneous binding sites in the polymers (33). The equilibrium dissociation constant of insulin $\left(K_{\mathrm{d}}\right)$ of insulin binding to MIP2 $(3.049 \mu \mathrm{mol} \mathrm{L}-1)$ was somewhat higher than MIP1 $\left(1.914 \mu \mathrm{mol}^{-1}\right)$, whereas the number of binding sites $\left(B_{\max }\right)$ was almost the same $\left(4 \mu \mathrm{mol} \mathrm{g}^{-1}\right)$ and clearly indicated the formation of uniform recognition sites (34).

\section{In vitro release studies}

To understand how the fluid environment affected the attached surface of the polymers, insulin release was performed under gastric and intestinal conditions ( $\mathrm{pH} 1.2$ and

a)

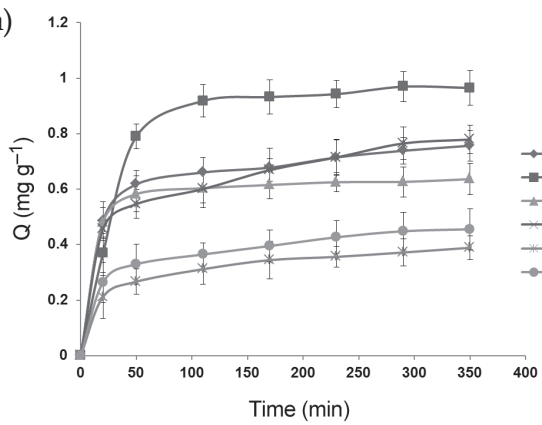

c)

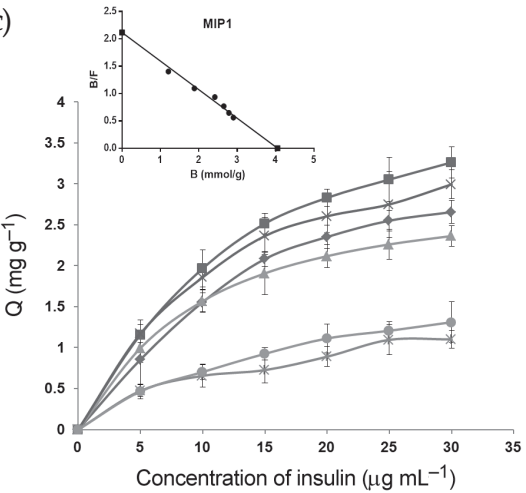

b)

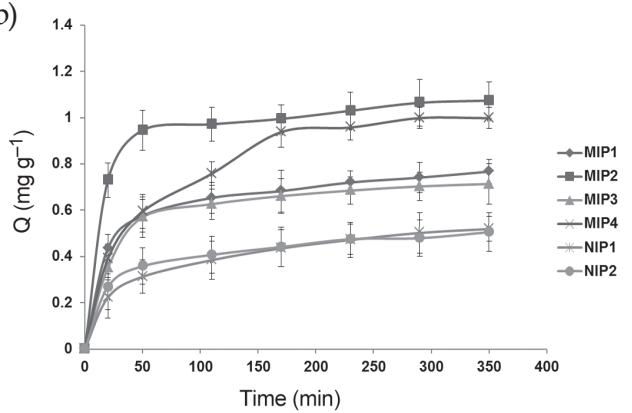

d)

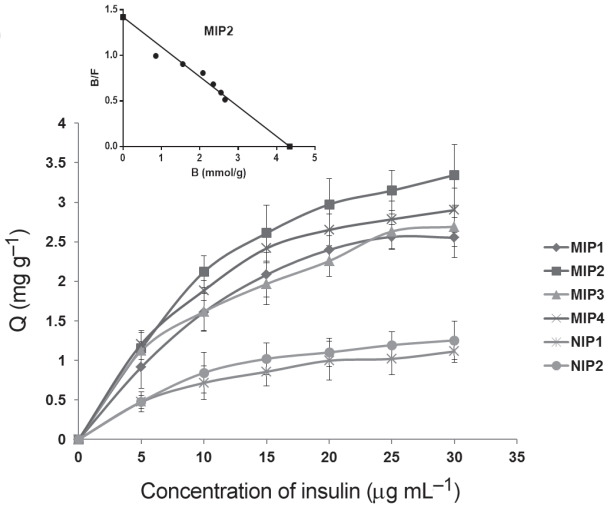

Fig. 4. a) Adsorption kinetic curves of MIPs and NIPs of F1 and b) F2 formulation at $25^{\circ} \mathrm{C}(\mathrm{pH}=7.4)$; c) Binding isotherm curves of MIPs and NIPs of F1 and d) F2 formulation at $25^{\circ} \mathrm{C}(\mathrm{pH}=7.4)$. Insets: Scatchard plot of insulin binding to MIP1 and MIP2 nanoparticles in PBS ( $\mathrm{pH}=7.4)$. 
a)
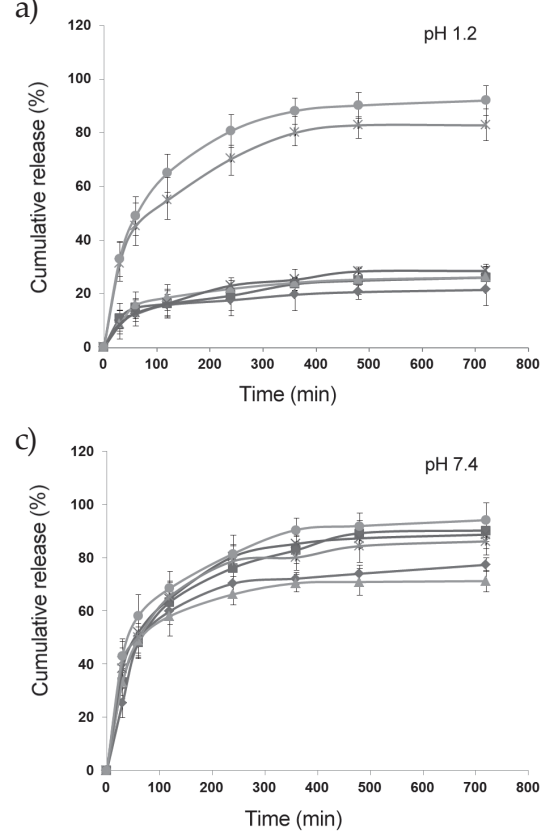

b)

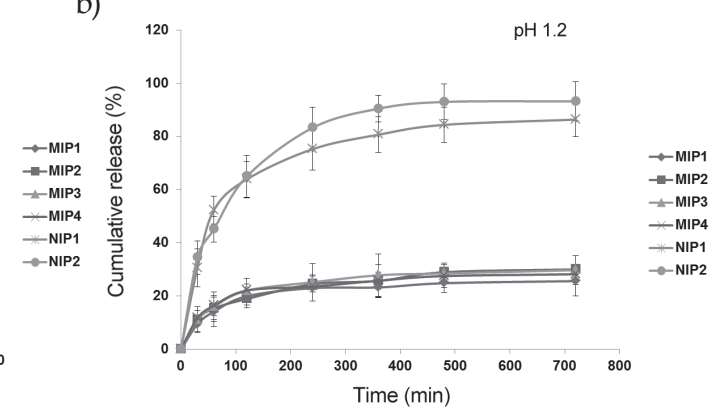

d)

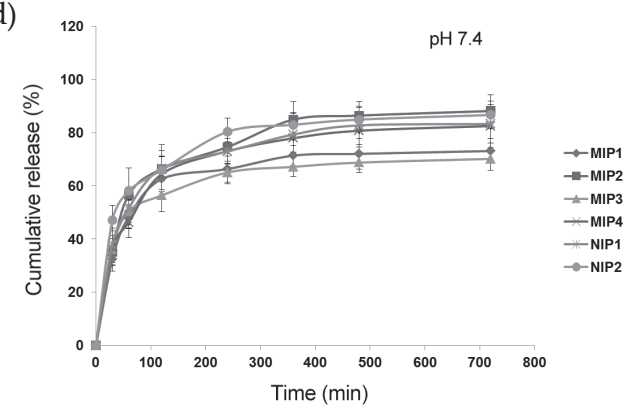

Fig. 5. Release profiles of insulin from MIPs and NIPs at $\mathrm{pH}$ 1.2: a) of formulation F1 and b) of F2; Release profiles of insulin from MIPs and NIPs at pH 7.4: c) of formulation F1 and d) F2.

7.4). At different $\mathrm{pH}$ values, the insulin release rate from MIPs for both F1 and F2 varied greatly compared to their corresponding NIPs. For MIPs at pH 1.2 (Fig. 5a), insulin release was retarded and less than $30 \%$ of insulin was released, whereas, at $\mathrm{pH} 7.4$, almost $90 \%$ of insulin was released from MIPs (Fig. 5c). In contrast, the release profiles of insulin from NIPs at both $\mathrm{pH}$ values were almost the same, about $90 \%$. This could be attributed to the absence of recognition sites in NIPs, which resulted in low interaction with the insulin and its subsequent release to the external medium (35). In basic medium ( $\mathrm{pH} 7.4$ ), a gradual release of insulin from MIPs (30-40\% in the first $30 \mathrm{~min}$ ) was observed, followed by sustained release (Fig. $5 \mathrm{c}$ and d). MIP2, which was produced by mixed functional monomers (MAA and HEAA) with a lower degree of cross-linkage, provided a considerably faster in vitro release $(k=7.35 \pm 0.89)$ than MIP1 $(k=4.73 \pm 2.57)$. MIP2 has a larger amount of MAA than MIP1 and offers a higher magnitude of solvated matrix, resulting in higher insulin release at basic $\mathrm{pH}$. In addition, better insulin release from MIP2 nanoparticles was further supported by a greater $K_{d}$ value of MIP2 $\left(3.049 \mu \mathrm{mol} \mathrm{L}^{-1}\right)$ than that of MIP1 $\left(1.914 \mu \mathrm{mol} \mathrm{L}^{-1}\right)$. Drug release data at $\mathrm{pH} 7.4$ were analyzed by the Korsmeyer-Peppas equation as follows:

$$
M_{t} / M_{\infty}=k t^{n}
$$

where $M_{t} / M_{\infty}$ is the fraction of insulin released at time $t$ and $k$ is the release rate constant. The diffusion exponent $n$ characterizes the release mechanism of the drug depending on the geometry of the material tested. For radial geometry, $n=0.45$ corresponds to the Fick- 

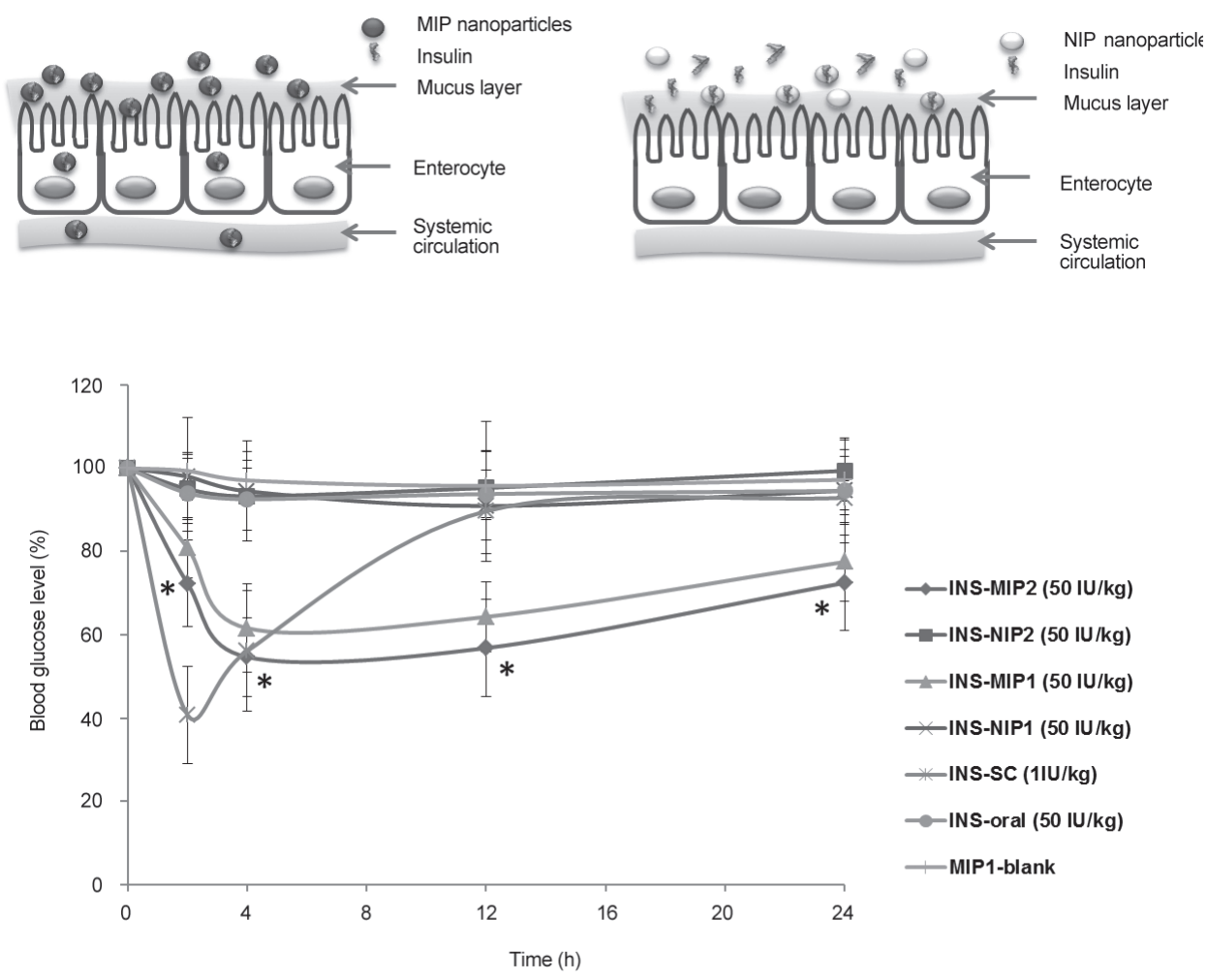

Fig. 6. Percentage reduction in blood glucose levels of diabetic rats after oral administration of insulin loaded MIPs and NIPs at a dose of (50 IU kg-1), or after subcutaneous injection of insulin solution at $1 \mathrm{IU} / \mathrm{kg}(n=5)$. *Statistically significant difference from the corresponding NIPs. Top: The proposed mechanism of delivery of insulin with biomimetic insulin-MIP by the transcellular nanoparticle transport mechanis

ian transport, $0.45<n<0.89$ corresponds to the non-Fickian (anomalous) transport, and $n=0.89$ is related to the case II transport (36). The diffusion exponent (n) values of MIP1 and MIP2 were found to be between 0.45 and 0.89 (see Table S4), implying non-Fickian transport. The results indicated a higher mode of insulin release in aqueous medium owing to the reduced mass transfer resistance of the protein in the imprinted matrix. The effect of the polymer mixture in this work was in agreement with the previous study of MAA and in the polyethylene glycol-based hydrogel $(37,38)$ enabling the interaction with the receptor on the membrane subsequent to insulin release to the medium. Nonetheless, the proximity of the protein receptor or the dense packing of the amino acid groups affected the insulin structure within imprints, as determined by confocal Raman spectroscopy, favoring the interaction of the insulin at its binding site surrounded by the crosslinked chains. Thus, they have different affinities for a significant proportion of dormant molecules upon exposure to the environment, and the underlying porous network maintaining the structural stability resulted in significant effects on protein release. 


\section{In vivo studies of insulin-loaded nanoparticles on diabetic rats}

Fig. 6 shows the blood glucose level-time profiles after oral administration of the insulin-loaded MIPs to diabetic rats. As can be seen, there was a sharp reduction in the blood glucose level ( $60 \%$ within 2-3 h) after the subcutaneous injection of the free form of insulin (INS-SC) at a dose of $1 \mathrm{IU} \mathrm{kg}^{-1}$; subsequently, the blood glucose level returned to its basal level with time. No obvious hypoglycemic effect was observed for the insulin solution (INS-oral) and the placebo control group (MIP1-blank) or either of the control polymers. After administration of both NIP nanoparticles loaded with insulin (INS-NIP1 and INS-NIP2) orally (50 IU kg-1), there was no change in the blood glucose level, which showed superimposable reductions of blood glucose level in all cases. In contrast, the blood glucose level was reduced markedly after oral administration of the insulin-loaded MIPs (50 IU kg-1). In comparison with both MIPs (INS-MIP1 and INS-MIP2), MIP1 showed the highest blood glucose level ( $39 \%$ in $4 \mathrm{~h}$ ) before gradual reduction, which lasted up to $12 \mathrm{~h}$, whereas MIP2 reduced the initial blood glucose level significantly $(p<0.05$; by $44 \%$ within $4 \mathrm{~h}$ ) and the blood glucose level was maintained at this level for up to $12 \mathrm{~h}$. These results indicated that the distribution of insulin-MIP was unaffected by the GI environment due to the stabilization of insulin by MIPs after oral administration.

The parameters of plasma glucose levels are given in Table IV, and at a dose of 50 IU $\mathrm{kg}^{-1}$, the relative pharmacological bioavailability in the percentage reduction of glucose of MIP1 and MIP2 was 1.73 and $1.55 \%$, respectively. In addition, the difference in the loading capacity between MIP2 and NIP2 was found to be 55.75 and $20.87 \mathrm{mg}$ insulin/g nanoparticles, respectively (Table S5). The loading capacity of MIPs was almost threefold higher than that for NIPs. As opposed to the nanoparticulate MIPs loaded with insulin, NIP failed to reduce the blood glucose level, due to the lack of specific binding sites within the polymer, resulting in no protein affinity. There was further improvement in insulin absorption in the case of MIP2 over MIP1, which was clearly observed because of the effect of insulin on the lipid-protein layer. The results showed that it increased the interactions of the biomolecule at the spatial motifs of the insulin template into the biological milieu in rat, that mimicked the insulin-cell surface interaction (39). This could be ascribed to the surface of MIP2 enabling surface adhesion of insulin-MIPs with a dense set of nanoscale pores. Oral administration of the insulin loaded MIPs to diabetic rats displayed a more significant

Table IV. Relative pharmacological bioavailability and parameters of plasma glucose levels $(\mathrm{n}=5)$

\begin{tabular}{lccc}
\hline Parameter & INS-MIP1 & INS-MIP2 & INS-SC \\
\hline Insulin dose $\left(\mathrm{IU} \mathrm{kg}^{-1}\right)$ & 50 & 50 & 1 \\
$C_{\min }{ }^{\mathrm{a}}\left(\mathrm{mg} \mathrm{dL}^{-1}\right)$ & $61.58 \pm 10.57$ & $54.65 \pm 9.43$ & $40.76 \pm 11.65$ \\
$t_{\min }{ }^{\mathrm{b}}(\mathrm{h})$ & 4 & 4 & 2 \\
$\mathrm{AAC}$ & $1577.71 \pm 208.29$ & $1422.88 \pm 254.90$ & $1816.2 \pm 188.96$ \\
$\mathrm{PA} \%$ & 1.74 & 1.55 & 100 \\
\hline
\end{tabular}

${ }^{\mathrm{a}} \mathrm{C}_{\min }$, minimum plasma glucose concentration (\% of initial)

${ }^{\mathrm{b}} t_{\text {min }}$, time at which $C_{\min }$ is attained; AAC, area above the blood glucose level-time curves; PA\%, relative pharmacological bioavailability. 
hypoglycemic effect than that of NIPs. Based on these important findings, we proposed insulin transport through the transcellular pathway (Fig. 6, top), related to the particle size, surface charge, and mucous adhesion in the GI tract, which would facilitate oral protein delivery. However, further investigations are required to make conclusions about the transport mechanisms.

\section{CONCLUSIONS}

We have successfully produced selective particles incorporating insulin and insulinbound islets by the molecular imprinting of protein on nanoparticles using the precipitation polymerization method. Biomimetic MIPs nanoparticles can serve as potential insulin oral delivery systems and represent a new way for an alternative platform, especially because of their robust physical structures, biocompatibility and loading capabilities. The MIPs exhibited much higher affinity toward the insulin with rapid adsorption kinetics, which enabled them to selectively deliver the therapeutic agent. The application of MIPs showed a different response of the blood glucose level, depending on the variation in the ratio of the functional monomer and cross-linkers. Targeted delivery of biomolecule recognition-based therapies such as insulin using the molecular imprinting approach could be effective for improvement of its therapeutic efficiency.

Acknowledgements. - We greatly appreciate financial support from the National Research University Project of Thailand, Office of the Higher Education Commission (Code no. PHA 540545c). Drug Delivery System Excellence Center at PSU; Nanotechnology Center (NANOTEC), Ministry of Science and Technology, Thailand, through its Center of Excellence Network program. The authors also thank the Department of Pharmaceutical Chemistry, Faculty of Pharmaceutical Sciences, for lab facilities, Mr. Maitri Nuanplub for his assistance in animal work and Dr. Brian Hodgson for helping us with the English. Supplementary material is available upon request.

\section{REFERENCES}

1. F. Nakayama, T. Yasuda, S. Umeda, M. Asada, T. Imamura, V. Meineke and M. Akashi, Fibroblast growth factor-12 (FGF12) translocation into intestinal epithelial cells is dependent on a novel cellpenetrating peptide domain involvement of internalization in the in vivo role of exogenous FGF12, J. Biol. Chem. 286 (2011) 25823-25834; DOI: 10.1074/jbc.M110.198267.

2. L. M. Ensign, R. Cone and J. Hanes, Oral drug delivery with polymeric nanoparticles: the gastrointestinal mucus barriers, Adv. Drug Deliv. Rev. 64 (2012) 557-570; DOI: 10.1016/j.addr.2011.12.009.

3. S. A. Zaidi, Latest trends in molecular imprinted polymer based drug delivery systems, RSC Adv. 6 (2016) 88807-88819; DOI: 10.1039/c6ra18911c.

4. R. Schirhagl, D. Podlipna, P. A. Lieberzeit and F. L. Dickert, Comparing biomimetic and biological receptors for insulin sensing, Chem. Commun. 46 (2010) 3128-3130.

5. R. Suedee, W. Naklua, S. Laengchokshoi, K. Thepkaue, P. Pathaburee and M. Nuanplub, Investigation of a self-assembling microgel containing an (S)-propranolol molecularly imprinted polymer in a native tissue microenvironment: Part I preparation and characterization. Part II biological application and testing, Process Biochem. 50 (2015) 517-544.

6. K. Eunkyung and C. Seung-Woo, Biomimetic polymer scaffolds to promote stem cell-mediated osteogenesis, Int. J. Stem Cells 6 (2013) 87-91.

7. R. Schirhagl, U. Latif, D. Podlipna, H. Blumenstock and F. L. Dickert, Natural and biomimetic materials for the detection of insulin, Anal. Chem. 84 (2012) 3908-3913. 
8. E. M. Kolonko, J. K. Pontrello, S. L. Mangold and L. L. Kiessling, General synthetic route to cellpermeable block copolymers via ROMP, J. Am. Chem. Soc. 131 (2009) 7327-7333.

9. F. Puoci, G. Cirillo, M. Curcio, O. I. Parisi, F. Iemma and N. Picci, Molecularly imprinted polymers in drug delivery: state of art and future perspectives, Expert Opin. Drug Deliv. 8 (2011) 1379-1393; DOI: 10.1517/17425247.2011.609166.

10. A. Viehof, L. Javot, A. Béduneau, Y. Pellequer and A. Lamprecht, Oral insulin delivery in rats by nanoparticles prepared with non-toxic solvents, Int. J. Pharm. 443 (2013) 169-174; DOI: 10.1016/j. ijpharm.2013.01.017.

11. E. Verspohl and H. Ammon, Evidence for the presence of insulin receptors in rat islets of Langerhans, J. Clin. Invest. 65 (1980) 1230; DOI: 10.1172/JCI109778.

12. D. R. Kryscio and N. A. Peppas, Critical review and perspective of macromolecularly imprinted polymers, Acta Biomater. 8 (2012) 461-473; DOI: 10.1016/j.actbio.2011.11.005.

13. L. Achar and N. Peppas, Preparation, characterization and mucoadhesive interactions of poly (methacrylic acid) copolymers with rat mucosa, J. Control. Release 31 (1994) 271-276; DOI: 10.1016/0168-3659(94)90009-4.

14. S. Li, E. N. Davis, X. Huang, B. Song, R. Peltzman, D. M. Sims, Q. Lin and Q. Wang, Synthesis and development of poly ( $n$-hydroxyethyl acrylamide)-ran-3-acrylamidophenylboronic acid polymer fluid for potential application in affinity sensing of glucose, J. Diabetes Sci. Technol. 5 (2011) 10601067.

15. J. Wang, P. A. Cormack, D. C. Sherrington and E. Khoshdel, Synthesis and characterization of micrometer-sized molecularly imprinted spherical polymer particulates prepared via precipitation polymerization, Pure Appl. Chem. 79 (2007) 1505-1519; DOI: 10.1351/pac200779091505.

16. G. Pan, Q. Guo, C. Cao, H. Yang and B. Li, Thermo-responsive molecularly imprinted nanogels for specific recognition and controlled release of proteins, Soft Matter 9 (2013) 3840-3850; DOI: 10.1039/C3SM27505A.

17. S. Chaitidou, O. Kotrotsiou, K. Kotti, O. Kammona, M. Bukhari and C. Kiparissides, Precipitation polymerization for the synthesis of nanostructured particles, Mater. Sci. Eng. B 152 (2008) 55-59; DOI: 10.1016/j.mseb.2008.06.024.

18. J. D. Carter, S. B. Dula, K. L. Corbin, R. Wu and C. S. Nunemaker, A practical guide to rodent islet isolation and assessment, Biol. Proced. Online 11 (2009) 3-31; DOI: 10.1007/s12575-009-9021-0.

19. H. He, D. Xiao, J. He, H. Li, H. He, H. Dai and J. Peng, Preparation of a core-shell magnetic ionimprinted polymer via a sol-gel process for selective extraction of $\mathrm{Cu}$ (ii) from herbal medicines, Analyst 139 (2014) 2459-2466; DOI: 10.1039/c3an02096g.

20. S. Sajeesh, K. Bouchemal, V. Marsaud, C. Vauthier and C. P. Sharma, Cyclodextrin complexed insulin encapsulated hydrogel microparticles: An oral delivery system for insulin, J. Control. Release 147 (2010) 377-384; DOI: 10.1016/j.jconrel.2010.08.007.

21. A. Cilek, N. Celebi, F. Tirnaksız and A. Tay, A lecithin-based microemulsion of rh-insulin with aprotinin for oral administration: Investigation of hypoglycemic effects in non-diabetic and STZinduced diabetic rats, Int. J. Pharm. 298 (2005) 176-185; DOI: 10.1016/j.ijpharm.2005.04.016.

22. W. Ritschel, G. Ritschel, B. Ritschel and P. Lücker, Rectal delivery system for insulin, Methods Find. Exp. Clin. Pharmacol. 10 (1988) 645-656.

23. M. P. Desai, V. Labhasetwar, G. L. Amidon and R. J. Levy, Gastrointestinal uptake of biodegradable microparticles: effect of particle size, Pharm. Res. 13 (1996) 1838-1845.

24. I. Stützer, D. Esterházy and M. Stoffel, The pancreatic beta cell surface proteome, Diabetologia 55 (2012) 1877-1889; DOI: 10.1007/s00125-012-2531-3.

25. M. García-Díaz, C. Foged and H. M. Nielsen, Improved insulin loading in poly (lactic-co-glycolic) acid (PLGA) nanoparticles upon self-assembly with lipids, Int. J. Pharm. 482 (2015) 84-91; DOI: 10.1016/j.ijpharm.2014.11.047. 
26. T. Andreani, A. L. R. de Souza, C. P. Kiill, E. N. Lorenzon, J. F. Fangueiro, A. C. Calpena, M. V. Chaud, M. L. Garcia, M. P. D. Gremião and A. M. Silva, Preparation and characterization of PEGcoated silica nanoparticles for oral insulin delivery, Int. J. Pharm. 473 (2014) 627-635; DOI: 10.1016/j. ijpharm.2014.07.049.

27. B. C. Tang, M. Dawson, S. K. Lai, Y.-Y. Wang, J. S. Suk, M. Yang, P. Zeitlin, M. P. Boyle, J. Fu and J. Hanes, Biodegradable polymer nanoparticles that rapidly penetrate the human mucus barrier, Proc. Natl. Acad. Sci. U.S.A. 106 (2009) 19268-19273; DOI: 10.1073/pnas.0905998106.

28. P. de Sousa Irene, M. Thomas, S. Corinna, F. Barbara and B.-S. Andreas, Insulin loaded mucus permeating nanoparticles: Addressing the surface characteristics as feature to improve mucus permeation, Int. J. Pharm. (2016); DOI: 10.1016/j.ijpharm.2016.01.022.

29. K. Rostamizadeh, H. Abdollahi and C. Parsajoo, Synthesis, optimization, and characterization of molecularly imprinted nanoparticles, Int. Nano Lett. 3 (2013) 1-9; DOI: 10.1186/2228-5326-3-20.

30. V. P. Drachev, M. D. Thoreson, E. N. Khaliullin, V. J. Davisson and V. M. Shalaev, Surface-enhanced Raman difference between human insulin and insulin lispro detected with adaptive nanostructures, J. Phys. Chem. B 108 (2004) 18046-18052; DOI: 10.1021/jp047254h.

31. H. Zeng, Y. Wang, X. Liu, J. Kong and C. Nie, Preparation of molecular imprinted polymers using bi-functional monomer and bi-crosslinker for solid-phase extraction of rutin, Talanta 93 (2012) 172-181; DOI: 10.1016/j.talanta.2012.02.008.

32. L. Xu, Y.-A. Huang, Q.-J. Zhu and C. Ye, Chitosan in molecularly-imprinted polymers: Current and Future Prospects, Int. J. Mol. Sci. 16 (2015) 18328-18347; DOI: 10.3390/ijms160818328.

33. M. Odabaşi, R. Say and A. Denizli, Molecular imprinted particles for lysozyme purification, $M a-$ ter. Sci. Eng. C 27 (2007) 90-99; DOI: 10.1016/j.msec.2006.03.002.

34. S. Scorrano, L. Mergola, R. Del Sole and G. Vasapollo, Synthesis of molecularly imprinted polymers for amino acid derivates by using different functional monomers, Int. J. Mol. Sci. 12 (2011) 1735-1743; DOI: 10.3390/ijms12031735.

35. M. R. Avadi, A. M. M. Sadeghi, N. Mohammadpour, S. Abedin, F. Atyabi, R. Dinarvand and M. Rafiee-Tehrani, Preparation and characterization of insulin nanoparticles using chitosan and arabic gum with ionic gelation method, Nanomedicine 6 (2010) 58-63; DOI: 10.1016/j.nano.2009.04.007.

36. C. Ferrero, D. Massuelle and E. Doelker, Towards elucidation of the drug release mechanism from compressed hydrophilic matrices made of cellulose ethers. II. Evaluation of a possible swellingcontrolled drug release mechanism using dimensionless analysis, J. Control. Release 141 (2010) 223-233; DOI: 10.1016/j.jconrel.2009.09.011.

37. S. Li, A. Tiwari, Y. Ge and D. Fei, A pH-responsive, low crosslinked, molecularly imprinted insulin delivery system, Adv. Mater. Lett. 1 (2010) 4-10; DOI: 10.5185/amlett.2010.4110.

38. E. Lee, K. Kim, M. Choi, Y. Lee, J.-W. Park and B. Kim, Development of smart delivery system for ascorbic acid using pH-responsive P (MAA-co-EGMA) hydrogel microparticles, Drug Deliv. 17 (2010) 573-580; DOI: 10.3109/10717544.2010.500636.

39. Y. Hoshino, T. Urakami, H. Koido and K. J. Shea, Recognition, neutralization, and clearance of target peptides in the bloodstream of living mice by molecularly imprinted polymer nanoparticles: A plastic antibody, J. Am. Chem. Soc. 132 (2010) 6644-6645; DOI: 10.1021/ja102148f. 